\title{
Geospatial Analysis of the Impact of Flood and Drought Hazards on Crop Land and Its Relationship with Human Migration at the District Level in Uttar Pradesh, India
}

\begin{abstract}
The main objective was to explore the connection between flood and drought hazards and their impact on crop land and human migration. The Flood and Drought effect on Cropland Index (FDCI), hot spot analysis and the Global Regression Analysis method was applied for the identification of the relationship between human migration and flood and drought hazards. The spatial pattern and hot and cold spots of FDCI, spatial autocorrelation and Getis-OrdGi* statistic techniques were used respectively. The FDCI was taken as an explanatory variable and human migration was taken as a dependent variable in the environment of the geographically weighted regression (GWR) model which was applied to measure the impact of flood and drought hazards on human migration. FDCI suggests a z-score of 4.9, which shows that the impact of flood and drought frequency on crop land is highly clustered. In the case of the hot spots analysis, out of seventy districts in Uttar Pradesh twenty-one were classified as hot spot and eight were classified as cold spots with a confidence level of 90 to $99 \%$. Hot spot indicate maximum and cold spots show minimum impact of flood and drought hazards on crop land. The impact of flood and drought hazards on human migration show that there are fourteen districts where migration out is far more than predicted while there are ten districts where migration out is far lower.
\end{abstract}

Keywords: flood, drought, migration, climate change, hot spot analysis, geographical weighted regression

Received: 17 June 2021; accepted: 23 September 2021

(C) 2021 Authors. This is an open access publication, which can be used, distributed and reproduced in any medium according to the Creative Commons CC-BY 4.0 License.

1 Adigrat University, Department of Geography and Environmental Studies, Ethiopia, email: zubairul@gmail.com, ORCID ID: https://orcid.org/0000-0002-6591-2241

2 K. Banerjee Centre of Atmospheric \& Ocean Studies, IIDS, Nehru Science Centre, University of Allahabad, Prayagraj, India, email: sudhirinjnu@gmail.com,

ORCID ID: https://orcid.org/0000-0001-8465-0649 


\section{Introduction}

Flood and drought frequency as well as crop land friction varies from one place to another and thus its impact is also not the same on human livelihood or migration. People have always migrated from one place to another due to environmental factors and human conflicts. Population and environment studies better helps the study of the relationship between migration and the environment. Further, global climate change has a substantial impact on human migration [1]. According to [2], in the early 1990 the main impact of climate change on human migration was due to coastal erosion, flooding and agricultural disruption. The change in the frequency of extreme events and erratic rainfall due to climate change has posed hydrological risks at a regional scale [3]. Yang et al. [4] outlined that more frequent flood and drought events have occurred after 1980s in the Huaihe River Basin, China. The UNDP [5] reported that India may suffer due to climate change in the coming years as most of its population depends on agriculture and forestry for their livelihoods. Parthasarathy et al. [6] studied the droughts and floods in summer monsoon season and highlighted the worst drought years as 1877, 1899, 1911, 1918, 1920, 1951, 1965 and 1972, while the worst flood years were 1892, 1933, 1961 and 1983. Indian states like Haryana, Punjab, west Rajasthan, and Gujarat (Saurashtra and Kutch sub-divisions) have high probabilities of flood and drought. Nath et al. [7] studied the spatio-temporal characteristics of drought in India and its impact in the Indo-Gangetic plain during the summer season (April-September) using Standardized Precipitation Evapotranspiration Index (SPEI). Perch et al. [8] used conceptual models for the investigation of the impact of sea level rises and floods on human migration. Flood related migration in urban and rural settings and its impact on human security in Malaysia were studied by Reza and Alatas [9]. Leighton [10] suggests that there are 25 million environmental migrants fleeing due to flood, drought, and desertification. Tran [11] has examined how land use change is linked to farmers' decisions to migrate in the Vietnamese Mekong Delta (VMD). Sarkar [12] has studied out-migration from Uttar Pradesh state, India and suggested the employment is the main reason for migration from Uttar Pradesh. Maharjan et al. [13] have studied rural out-migration and agricultural land use change in the Gandaki Basin, Nepal. The literature suggests that the majority of researchers are working on climate change and its associated impact on land use/land cover, forestry and the livelihood of the people [14]. Few researchers have also studied the probabilities of flood and drought, but in the current work an attempt was made to study the human migration due to these factors.

To meet the general objectives, four specific ones were set as follows:

1) to develop an index of flood and drought effect on cropland area,

2) to calculate the spatial pattern of FDCI in the study area,

3) to find the Hot spot of FDCI, and

4) to measure the impact of flood and drought hazards on human migration. 


\section{Materials and Methods}

\subsection{Study Area}

The state of Uttar Pradesh is a highly populated state in India (Fig. 1). The total geographical area is $243,290 \mathrm{~km}^{2}$, and it is the fourth-largest state in the country in terms of land area. It shares an international border with Nepal in the north. The Gangetic Plain region has a dense network of rivers and forms the Ganges-Yamuna Doab, the Ghaghara plains, the Ganges plains and the Terai and has very high fertile land.

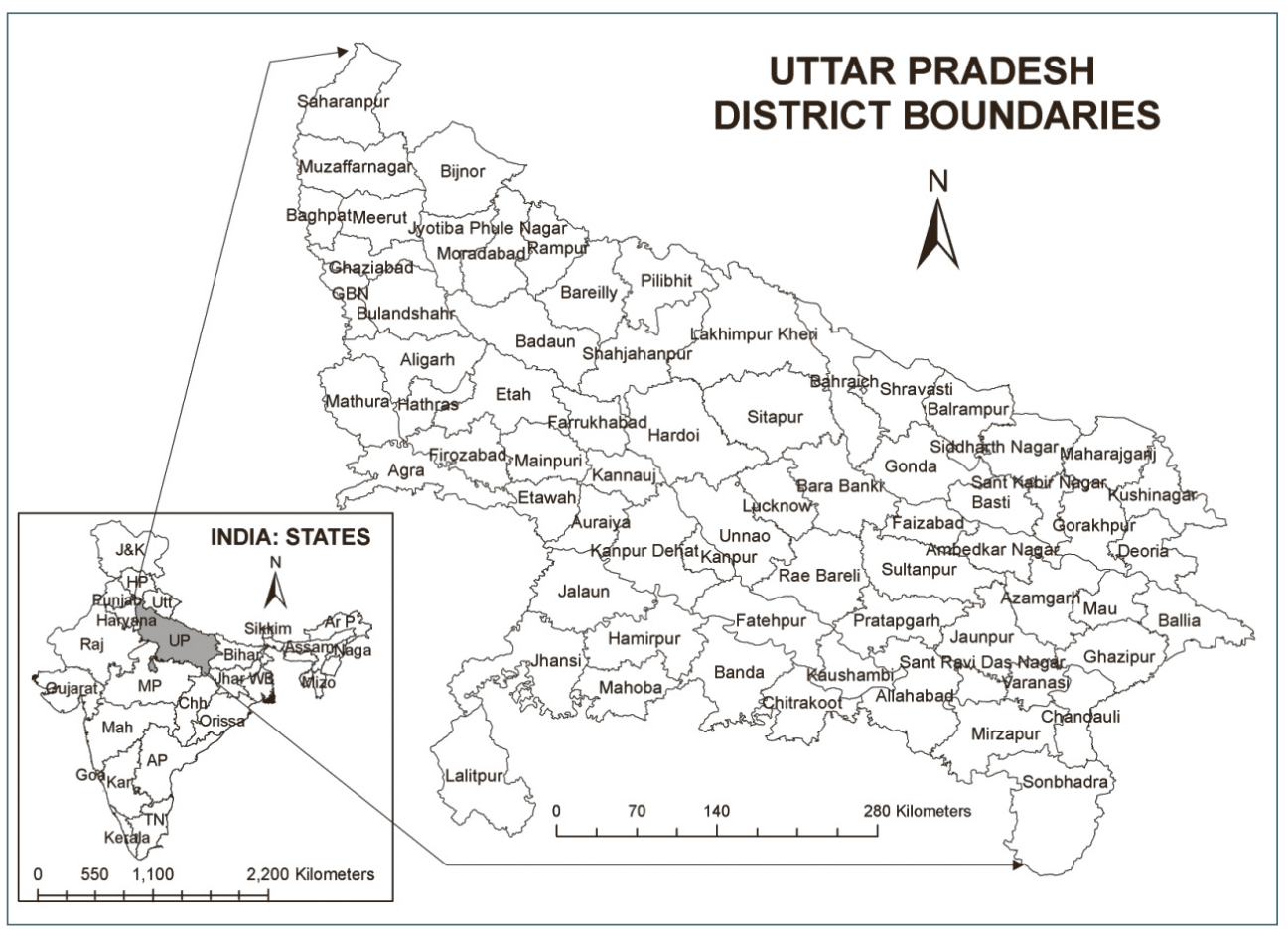

Fig. 1. Location map of the study area

\subsection{Data Used}

Satellite data obtained from SPOT and MODIS were combined with agricultural inventory data to generate a global data set of croplands, v1 (2000). Ramankutty et al. [15] created the data and freely distributed it through the Columbia University Center for International Earth Science Information Network (CIESIN). Global Flood Hazard Frequency and Distribution, v1 (1985-2003) data is available at a 2.5 minute grid was used to assess the relative distribution and frequency of global flood 
hazards. The data was developed by the Dartmouth Flood Observatory and was georeferenced to the nearest degree.

Global Drought Hazard Frequency and Distribution, v1 (1980-2000) data was used to assess the relative distribution and frequency of drought hazards. The data is available at a 2.5 minute grid. The average monthly precipitation data collected from 1980-2000 was used with a resolution of 2.5 degrees. Drought events are identified when the magnitude of a monthly precipitation deficit is less than or equal to $50 \%$ of its long-term median value for three or more consecutive months.

Global Estimated Net Migration Grids By Decade, v1 (1970-2000) was used to estimate net-migration per one-kilometer grid cell on a decadal basis for the 1970s, 1980s, and 1990s and provide migration information over the three decades from 1970 to 2000. Net migration was estimated by subtracting the population in time period 2 from the population in time period 1, and then subtracting the natural increase (births minus deaths). The residual was considered to be net migration (in-migrants minus out-migrants).

\subsection{Data Analysis}

Four steps were applied in this work and which are as follows:

Step 1: To develop the index and to relate flood and drought hazards to crop land friction, the following method was applied as mentioned in Equation (1):

$$
\mathrm{FDCI}=\mathrm{CLF} \cdot \mathrm{DHF} \cdot \mathrm{FHF}
$$

where:

FDCI - flood and drought effect on cropland index,

CLF - crop land friction,

DHF - drought hazard frequency,

FHF - flood hazard frequency.

Step 2: To calculate the spatial pattern of flood and drought hazards in relation to crop land friction, a spatial autocorrelation analysis was performed based on feature locations and attribute value using the global Moran's I statistic. In this process, an inverse distance weighted model was conceptualized, the Euclidean distance method was selected and the distance threshold was given as 102,364.5 meters.

Step 3: Hot spot analysis helps to identify statistically significant map of hot and cold spots [16]. To find flood and drought hazard hot spot in relation to crop land friction, the hot spot analysis tool was used to calculate the Getis-OrdGi* statistic (pronounced G-i-star) for each feature in a dataset.

Step 4: Geographically weighted regression (GWR) analysis helps to explore spatially varying relationships $[17,18]$. To measure the impact of flood and drought hazards on human migration, geographically weighted regression was used; it is a local form of linear regression which is used to model spatially varying relationships. The flood and drought cropland index was taken as explanatory variable $(x)$ 
and human migration as dependent variables $\left(y_{i}\right)$. The regression Equation (2) is expressed as:

$$
y_{i}=\beta_{0}+\sum \beta_{k} x_{k i}+\varepsilon_{i}
$$

where:

$y_{i}$ - dependent variable,

$\beta_{0}$ - the $y_{i}$ intercept,

$x_{k i}$ - the independent variables/explanatory variable,

$i, k$ - index varies $(i=1,2, \ldots, n ; k=1,2, \ldots, p)$,

$\beta_{k}$ - regression coefficients,

$\varepsilon_{i}-$ residuals/random error.

The regression Equation (3) for each observation was expressed as follows:

$$
y_{i}=\beta_{0}\left(u_{i}, v_{i}\right)+\sum \beta_{k}\left(u_{i}, v_{i}\right) x_{k i}+\varepsilon_{i}
$$

where:

$$
\begin{aligned}
& y_{i}- \text { dependent variable, } \\
& \beta_{k}-\text { regression coefficients, } \\
& x_{k i}-\text { independent variables, } \\
&\left(u_{i^{\prime}} v_{i}\right) \text { - the coordinate location of } i \\
& \varepsilon_{i}-\text { error term. }
\end{aligned}
$$

The estimator of the model as given in Equation (4):

$$
\beta^{\prime}=\left[X^{T} W\left(u_{i}, v_{i}\right) X\right]^{-1} X^{T} W\left(u_{i}, v_{i}\right)
$$

where:

$W\left(u_{i^{\prime}} v_{i}\right)$ - a square matrix of weights specific to location $\left(u_{i^{\prime}} v_{i}\right)$ of study area, $X^{T} W\left(u_{i^{\prime}}, v_{i}\right) X$ - geographically weighted variance-covariance matrix $[18,19]$.

\section{Results and Discussion}

The result for flood and drought effect on cropland index (FDCI) of Uttar Pradesh is given in Table 1. Figure 2 shows the flood and drought effect on cropland at the district level. The districts which have higher effects are also having high crop land friction and experiences more drought and flood conditions. The districts of eastern Uttar Pradesh encounter more flood hazards while the western side experiences more drought conditions. The districts having lower effects are as Lalitpur, Gautam Budh Nagar, Sonbhadra, Lakhimpur Kheri, Kanpur Dehat, Chitrakoot, Hathras, Mahoba, Mirzapur, Balrampur, Bahraich, Chandauli, Unnao, and Lucknow. There are two major reasons for this, since these districts have either a low crop land area or the flood or drought frequency is low. The spatial pattern of FDCI in the study area 
is highly clustered. The z-score is 4.9 , which shows that there is a less than $1 \%$ likelihood that this high-clustered pattern could be the result of random chance.

Table 1. Flood and drought effect on cropland index

\begin{tabular}{|l|c||}
\hline \multicolumn{1}{|c|}{ FDCI } & Value [\%] \\
\hline \hline Minimum & 8.4 \\
\hline Maximum & 72.4 \\
\hline Mean & 51.6 \\
\hline Standard Deviation & 13.03 \\
\hline
\end{tabular}

Figure 3 shows the hot and cold spots, with two hot spot due to drought conditions which are clearly visible in western Uttar Pradesh. However, in eastern Uttar Pradesh, the hot spots are formed due to flood conditions. The cold spots in the southern districts are due to the low friction of crop land there. Figure 4 shows the impact of flood and drought hazards on human migration. The $r^{2}$ as 0.37 indicate that there is a positive relation between FDCI and human out migration based on GWR. It suggests that $37 \%$ of migration is due to drought and floods. The migration is highest from those districts which are more affected due to flood and drought hazards.

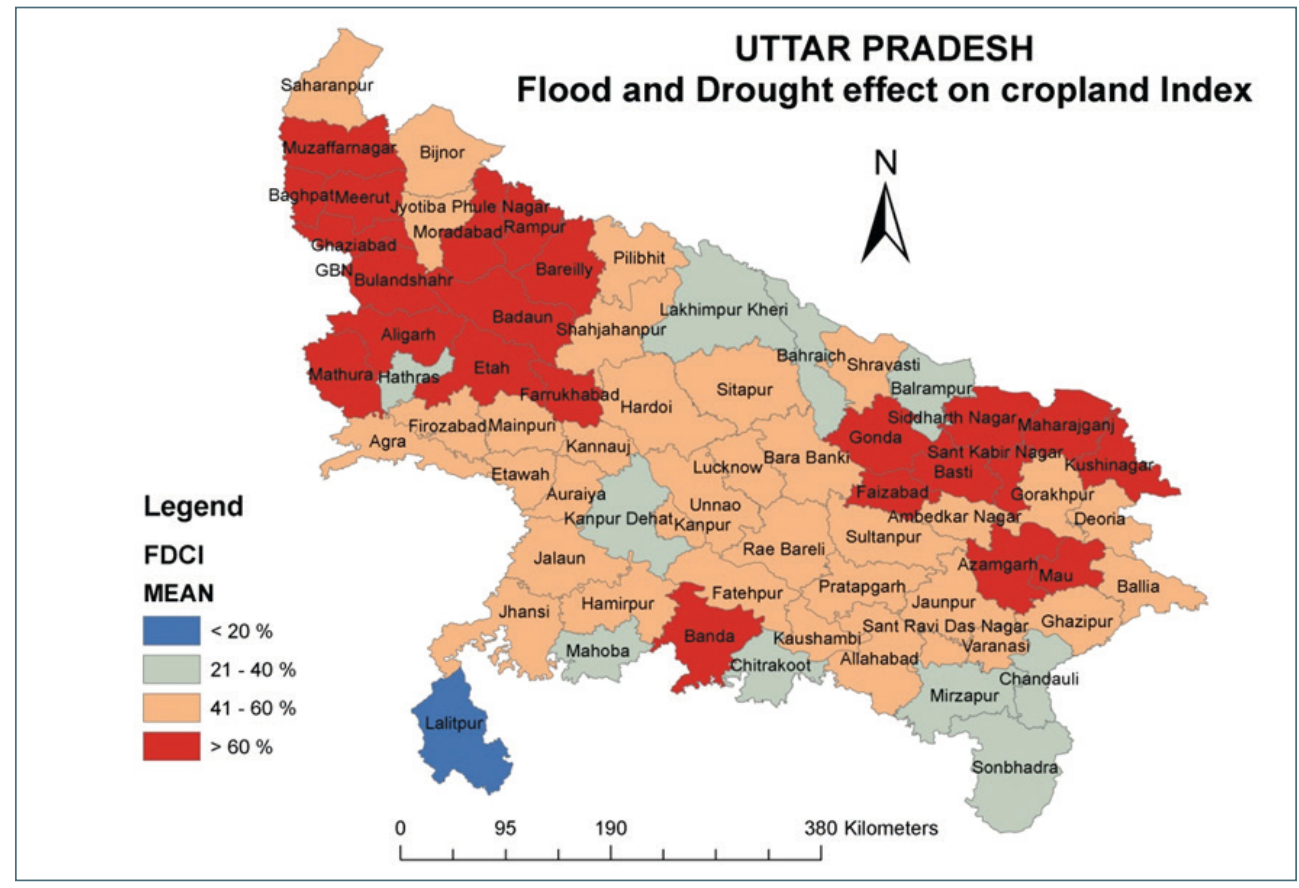

Fig. 2. Flood and drought effect on cropland index 


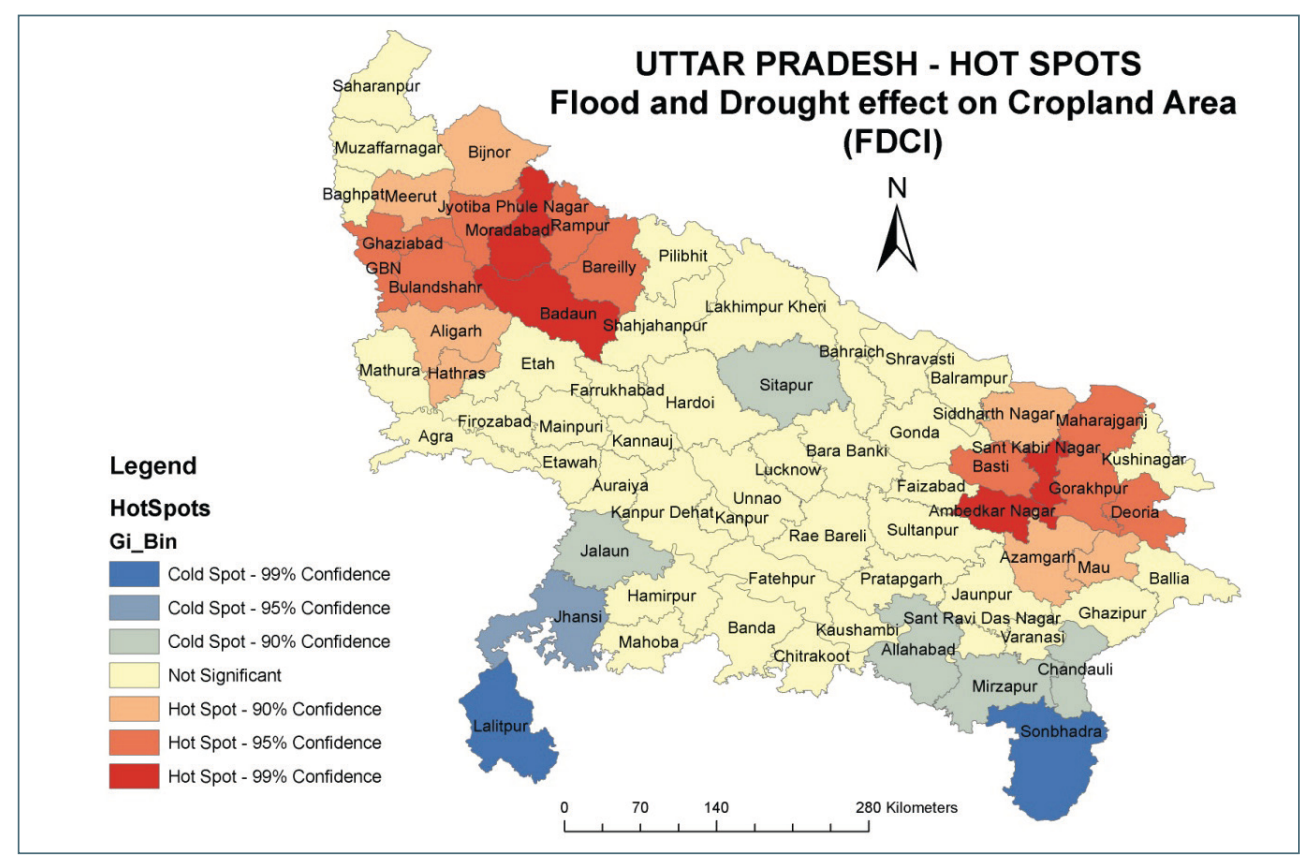

Fig. 3. Hot spot map of flood and drought effect on cropland area

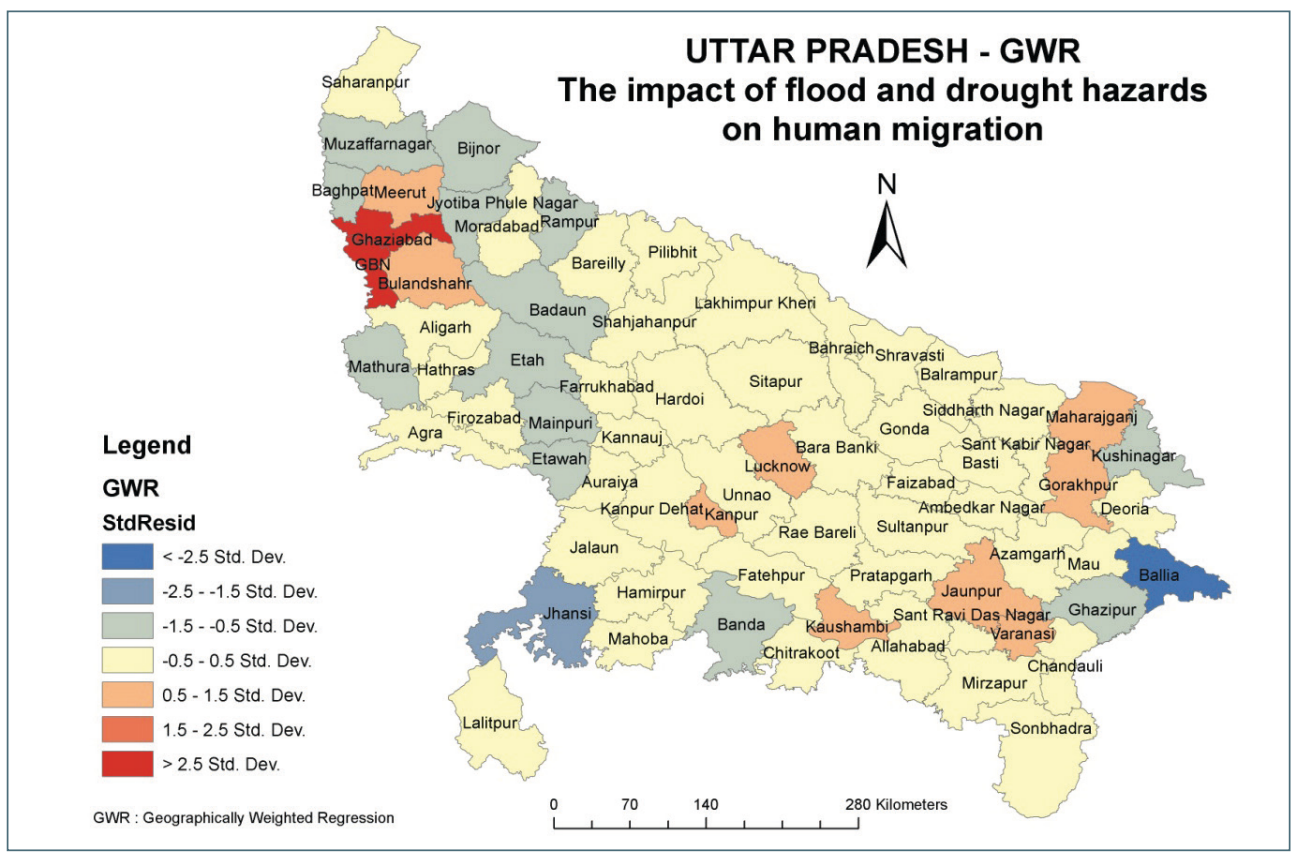

Fig. 4. The impact of flood and drought hazards on human migration 


\subsection{Hot Spots of the Flood and Drought Effect on Cropland Area (FDCI)}

The FDCI is categorized into four zones as $<20 \%, 21-40 \%, 41-60 \%$ and $>60 \%$. The majority of the area falls in the zone of $21-40 \%$ category. Only one district, Lalitpur, has a mean FDCI value of less than $<20 \%$. The districts located in the northern-western part are under recurrent flood and drought. These districts have dense river networks while districts in the north-eastern side of the state are very close to the Himalayan mountain range and under continuous threat of flooding. Therefore the districts which falls in zone of $>60 \%$ are under severe threat of flood and drought which affect the cropland (Fig. 2).

The hot spot analysis suggests that there are seven categories, out of which three categories are cold spots, three are hot spots and one category is non-significant. The hot spot/cold spot analysis was carried out $90 \%, 95 \%$ and $99 \%$ confidence interval. At a $95 \%$ confidence interval there are only two districts, Lalitpur and Sonbhadra, which are more prone to drought conditions. The majority of the districts of the state are in the not significant hot spot category. The districts of Badaun, Moradabad and Ambedkar Nagar are in the high hot spot category at 99\% significant level (Fig. 3).

\subsection{Impact of Flood and Drought Hazards on Human Migration}

The GWR has seven categories of standard deviation. The Ghaziabad district falls in the $>2.5$ order of standard deviation and the lowest was reported for the Ballia district (<-2.5 standard deviation). The majority of districts show from -0.5 to 0.5 standard deviation. Two districts have in the range of 1.5-2.5 standard deviations whereas four districts are in the 0.5-1.5 standard deviation category. Three districts fall in the -1.5 to -0.5 standard deviation category (Fig. 4). There is $r^{2}=0.37$ value between the dependent and explanatory variables and it is positive in magnitude. The Ghaziabad district reported the highest standard deviation as it is very near to the national capital of India i.e. New Delhi, hence lots of people migrate from the rest of the state to the district in search of employment and improved quality of life.

The migration of male and females have due to different reasons as the main reason for male migration is employment, while female migration is driven by both marriage and employment in the state [12]. The other reason for migration is the pursuit of higher education. The world is facing the issue of environmental migration [9] and this socio-political issue has become increasingly important. Human movement due to environmental migration or migration due to terrorism is less understood, hence the need to analyze, monitor and predict change. Similarly, detailed studies on the causes of environmental migration are globally lacking at present. 


\section{Conclusions}

Droughts and floods are inherent features of the monsoonal landscape. Floods are local whereas droughts are regional in nature. Drought and flood frequency has altered due to climate change. Every year, millions of hectares of land are affected by floods and drought in India. The frequency of droughts and floods affects crops health and yield. Human migration is due to many environmental, social, economic and cultural factors. The state has a high level of unemployment, regional imbalances, and widespread poverty are characteristics of Uttar Pradesh state. The urban and rural areas also experience migration and it needs to be predicted and evaluated. In this work we have explored the relationship between human migration due to drought and flood and its impact on crop land. Inter-district and intra-district migration are also common in the state. The results suggest the migration of people from different parts of the study area is different due to varying hydro-climatic extremes (droughts and floods). The GWR result shows that the district which is near to the capital reported the highest migration. It suggests that $37 \%$ of migration is due to drought and floods. In a few districts the rates of urbanization and industrial development is low, and generally these areas are more affected by such events. In turn, this means that people leave these districts to seek out alternative work and educational opportunities. The highest concentration of migrants is found in the district which is a hub of Micro, Small and Medium Enterprises, the construction sector and the service sector. For sustainable development it is very important to identify districts with high chances of migration. A limitation of this study is that we have only considered two factors, therefore we recommend considering a greater number of factors like regional setting, culture, caste and other physical and socio-economic factors for more reliable results. This research will help policy makers to plan appropriate projects to sustain the livelihood of local people, especially in those districts where outmigration is far more than predicted.

\section{Acknowledgements}

The first author would like to thank the Center for International Earth Science Information Network, Columbia University for creating and providing data through the NASA Socioeconomic Data and Applications Center (SEDAC). The second author (SKS) acknowledges SERB, New Delhi, India for its generous financial support (Grant no. CRG/2019/003551).

\section{Conflict of Interest}

The authors declare no conflicting financial interests.

\section{Author Contribution}

Zubairul Islam: data downloading, data preparation analysis, drafting. Sudhir Kumar Singh: data analysis, drafting, review and corrections. 


\section{References}

[1] Adamo S.B., Izazola H.: Human migration and the environment. Population and Environment, vol. 32(2-3), 2010, pp. 105-108. https://doi.org/10.1007/ s11111-010-0130-0.

[2] Lonergan S.: The role of environmental degradation in population displacement. Environmental Change and Security Project Report, iss. 4, Spring 1998, pp. 5-15.

[3] Lehner B., Döll P., Alcamo J., Henrichs T., Kaspar F.: Estimating the impact of global change on flood and drought risks in Europe: a continental, integrated analysis. Climatic Change, vol. 75(3), 2006, pp. 273-299. https://doi.org/10.1007/ s10584-006-6338-4.

[4] Yang C., Yu Z., Hao Z., Zhang J., Zhu J.: Impact of climate change on flood and drought events in Huaihe River Basin, China. Hydrology Research, vol. 43(1-2), 2012, pp. 14-22. https://doi.org/10.2166/nh.2011.112.

[5] United Nations Development Programme (UNDP): India. https://www. adaptation-undp.org/explore/india [access: 30.04.2020].

[6] Parthasarathy B., Sontakke N.A., Monot A.A., Kothawale D.R.: Droughts/ floods in the summer monsoon season over different meteorological subdivisions of India for the period 1871-1984. Journal of Climatology, vol. 7(1), 1987, pp. 57-70. https://doi.org/10.1002/joc.3370070106.

[7] Nath R., Nath D., Li Q., Chen W., Cui X.: Impact of drought on agriculture in the Indo-Gangetic Plain, India. Advances in Atmospheric Sciences, vol. 34(3), 2017, pp. 335-346. https://doi.org/10.1007/s00376-016-6102-2.

[8] Perch-Nielsen S.L., Bättig M.B., Imboden D.: Exploring the link between climate change and migration. Climatic Change, vol. 91(3-4), 2008, 375. https://doi.org/ 10.1007/s10584-008-9416-y.

[9] Reza M.I.H., Alatas S.M.: Migration in the Context of Disaster Management: Governance, Vulnerabilities and Security a Malaysian perspective. [in:] International Conference, On the Move: Critical Migration Themes in ASEAN, Chulalongkorn University, Thailand, 2012. http://dx.doi.org/10.13140/2.1.3997.1846.

[10] Leighton M.: Desertification and migration. [in:] Johnson P.M., Mayrand K., Paquin M. (eds.), Governing Global Desertification: Linking Environmental Degradation, Poverty and Participation, Ashgate, Hampshire 2006, pp. 43-58. https://doi.org/10.4324/9781315253916.

[11] Tran T.A.: Land use change driven out-migration: Evidence from three flood-prone communities in the Vietnamese Mekong Delta. Land Use Policy, vol. 88, 2019, 104157. https://doi.org/10.1016/j.landusepol.2019.104157.

[12] Sarkar P.: An overview of out-migration from Uttar Pradesh using census 2011. Journal of Migration Affairs, vol. II(2), 2020, pp. 58-66. https://doi.org/ 10.36931/jma.2020.2.2.58-66. 
[13] Maharjan A., Kochhar I., Chitale V.S., Hussain A., Gioli G.: Understanding rural outmigration and agricultural land use change in the Gandaki Basin, Nepal. Applied Geography, vol. 124, 2020, 102278. https://doi.org/10.1016/ j.apgeog.2020.102278.

[14] Berlemann M., Tran T.X.: Climate-Related Hazards and Internal Migration Empirical Evidence for Rural Vietnam. Economics of Disasters and Climate Change, vol. 4(2), 2020, pp. 385-409. https://doi.org/10.1007/s41885-020-00062-3.

[15] Ramankutty N., Evan A.T., Monfreda C., Foley J.A.: Global Agricultural Lands: Croplands, 2000. NASA Socioeconomic Data and Applications Center (SEDAC), Palisades, NY, 2010. https://doi.org/10.7927/H4C8276G.

[16] Center for Hazards and Risk Research - CHRR - Columbia University, and Center for International Earth Science Information Network - CIESIN - Columbia University: Global Flood Hazard Frequency and Distribution. NASA Socioeconomic Data and Applications Center (SEDAC), Palisades, NY, 2005. https://doi.org/10.7927/H4668B3D [access: 5.04.2020].

[17] Islam Z., Ranganathan M., Bagyaraj M., Singh S.K., Gautam S.K.: Multidecadal groundwater variability analysis using geostatistical method for groundwater sustainability. Environment, Development and Sustainability, 2021, pp. 1-19. https://doi.org/10.1007/s10668-021-01563-1.

[18] Lewandowska-Gwarda K.: Geographically weighted regression in the analysis of unemployment in Poland. ISPRS International Journal of Geo-Information, vol. 7(1), 2018, pp. 1-16. https://doi.org/10.3390/ijgi7010017.

[19] Columbia Public Health: Population Health Methods - Geographically Weighted Regression. https://www.publichealth.columbia.edu/research/populationhealth-methods/geographically-weighted-regression/ [access: 27.08.2021]. 